\title{
Development of a Software for the Basic Learning of Sign Language in the Eastern of the State of Yucatán, México
}

\author{
Joel C. Cupul Mooํㅡ, Victor M. Chi Pech ${ }^{2}$, Lizzie E. Narváez Díaz ${ }^{3}$, Jorge F. Uc Ciau ${ }^{4}$, \\ Erika R. Llanes Castro 5 \\ Faculty of Mathematics, Autonomous University of Yucatán, Mérida, Yucatán, México ${ }^{1-5}$
}

\begin{abstract}
The objective of the present work is to show the development of a software employed as tool for the basic learning of sign language, which will allow to reduce the divide of lack of communication that exists between people whether or not they suffer from an auditory problem. The success of this communication is of great importance since the human being today could not understand life without the ability to access the information that at all times is being generated in all areas. The interface of the software presented to the user is friendly and intuitive, allowing the user to learn its use in an easier way.
\end{abstract}

Keywords: Software, sign language, teaching, child deafness.

\section{INTRODUCTION}

Technological advances are currently highly related to all areas of knowledge and, therefore, of society; being the computer one of the main tools employed for communication and information management through several computer programs.

Some schools promote interactive teaching, with the clear intention that this will lead to improvements in student learning. Technical and pedagogical interactivity points a path towards a greater focus on learning objectives during classroom activities, in order to enable students to be more autonomous in exploiting the possibilities of information and communication technologies [1].

Nowadays children with hearing problems attend school and, consequently, they, their teachers and their classmates must be able to communicate with each other, one of these forms of communication being sign language.

Child deafness is a problem that affects both parents and their children who suffer from this disability since they cannot communicate with each other and it is known that human beings feel the need to be able to communicate with the people around them. The fact that deafness obstructs communication affects the cognitive process of the affected persons since, not being able to communicate, they have problems assimilating or understanding the things that they should learn like the persons without this disability.

In the case of a child with this disability, he or she is emotionally affected from an early age, since not being able to communicate with his parents creates a barrier in the bond between both.

Currently, human beings could not understand life without the ability to access the information that is being generated at all times in all areas. Oral communication is the most common form that allows human beings to participate in all environments of society, however, when a person is born or acquires a hearing disability, he or she is impeded, the possibility of achieving true social fulfillment is reduced in an important way. The difficulty of people with hearing disabilities to communicate with others, hinders their educational, professional and human development, consequently their opportunities for inclusion are limited, faced with this need, deaf people have developed their own form of communication, one of them is the Mexican Sign Language, which is one of the sign languages around the world. However, although this allows them to communicate with each other, it does not always facilitate the relationship with the rest of the community, especially with listeners who do not know that language [2].

In order to contribute to reducing this communication problem, it was decided to develop in the Visual Basic programming language a software that at first instance is used in elementary schools in the eastern part of the State of Yucatán, specifically in the city of Tizimín, located 160 kilometers from the state capital.

This computer program will help people who cannot go to a multiple care center or rehabilitation unit to receive their language therapy, receive it at their school, home, or anywhere they are learning sign language through a computer software. 


\section{International Advanced Research Journal in Science, Engineering and Technology}

Vol. 7, Issue 11, November 2020

\section{DOI 10.17148/IARJSET.2020.71107}

\section{Sign Language}

Sign language is essential to ensure the full participation of deaf people in their communities, as well as the full realization of their human rights.

The Mexican Sign Language is composed of visual signs with their own linguistic structure, with which deaf people are identified and expressed in Mexico. For the vast majority of those who have been deaf since birth, childhood or early youth, this is the language in which they articulate their thoughts and emotions, which allows them to satisfy their communication needs, as well as develop their cognitive abilities to the maximum while interacting with the world around them [2].

Sign language is a language that deaf children can learn naturally. However, $95 \%$ have hearing families who generally do not know sign language, so most of these children receive late exposure to sign language, resulting in late cognitive development and less chance of acquiring language proficiency. Therefore, deaf children must have the right to early access to sign language and consequently the families of these children must receive education and learning of sign language.

Sign languages have variations from community to community or by geographic regions. Like any other language, they have vocabulary, syntax and grammar. They users use articulate gestures signs with their hands accompanied by facial expressions, glances and body movements to express concepts or ideas. The UN assembly states that early access to sign language and the services through these, including a quality education in that language, is vital for the growth and development of deaf people and crucial for the achievement of sustainable development goals. Likewise, it also highlights the importance of preserving sign languages as part of linguistic and cultural diversity [3].

According to data from the 2010 Population and Housing Census, 12.1 per cent of the 5 million 739 thousand people with some form of disability had a limitation to listen even with the use of a hearing aid; this places listening limitations as the third cause of disability in Mexico. From the medical model, deafness is considered only as a hearing impairment, and the focus is on rehabilitation through technological aids, surgical interventions (cochlear implant), oralization, among others, to solve the barriers faced by deaf people [4].

\section{III.DESIGN OF THE SOFTWARE}

For the development of the software there was first designed the interface and the different buttons, as well as the objects implemented in it. Subsequently, it was defined the behavior of the interface and each of its scenarios and objects in the Visual Basic programming language. In each scenario several attractive visuals were implemented and always keeping in mind to be a support in the sign language learning process.

\section{IV.RESULTS}

As a result of this work, it was obtained a software to learn sign language, which has a teaching-learning approach that consists first of learning the alphabet of the sign language, as well as some basic words to engage in a not-so-complex conversation. In the same way, the software shows how to perform the sign language as well as its hand movements. Likewise, it also includes an evaluation of what has been learned with software.

To start the execution of the computer program, the user must make click on its associated icon. Then, the start menu will open, where the user is shown the "instructions" option to read the instructions on using the program, the "start" option to start the lessons for learning the sign language, and the option to exit the program, as seen in Figure 1.

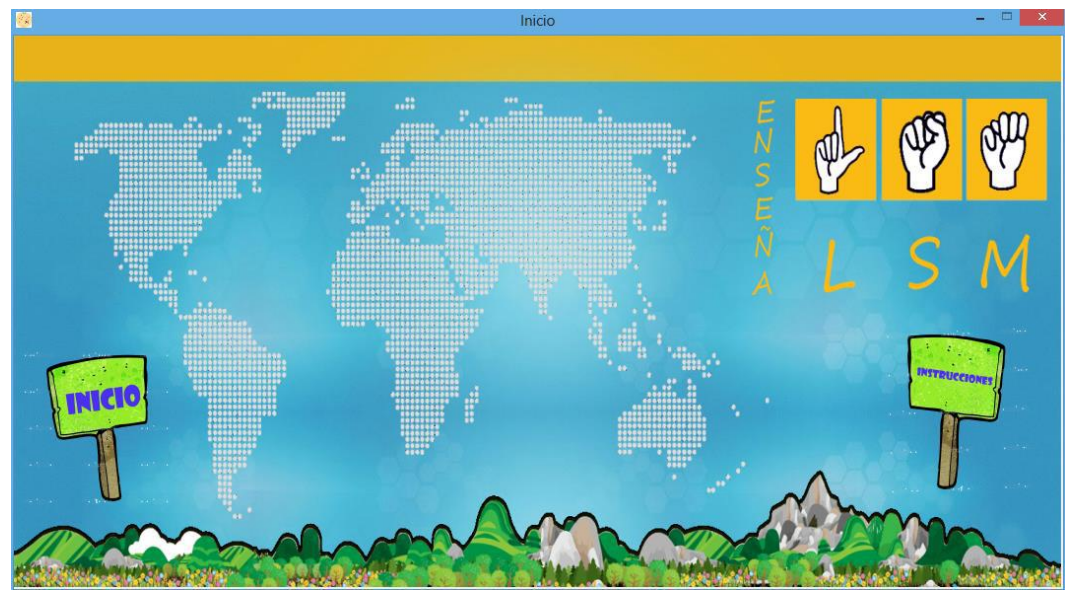

Fig. 1 Main screen of the software. 


\section{International Advanced Research Journal in Science, Engineering and Technology}

Vol. 7, Issue 11, November 2020

\section{DOI 10.17148/IARJSET.2020.71107}

When choosing the "start" option, the user will be displayed a window in which he or she can start with the basic level of learning of the sign language, as shown in Figure 2. Once this is presented the user should click on the "beginner" button to get started.

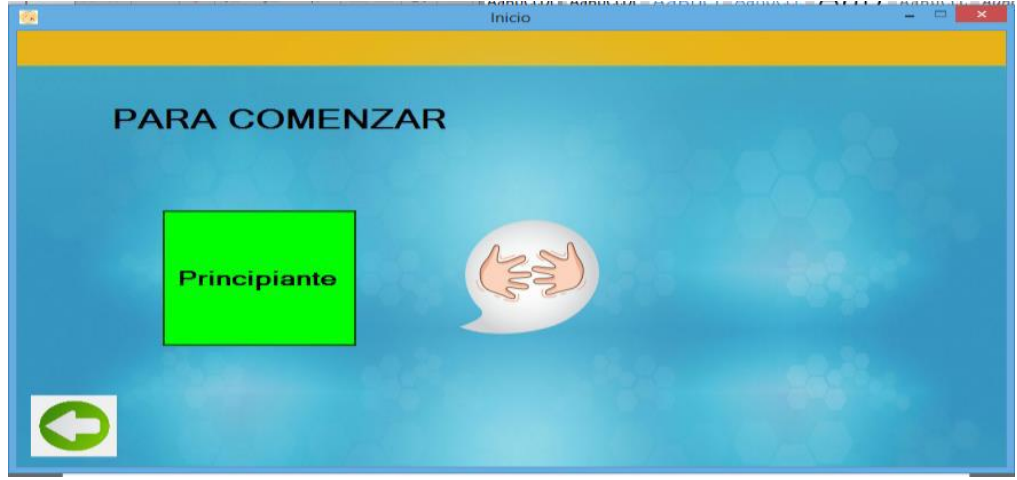

Fig. 2 Screen to start the game.

Clicking on the beginner button presents the user with a window called "learn the alphabet" with all the letters of the alphabet. Clicking on one of them presents the corresponding image in the sign language. Figure 3 shows the image obtained by clicking the button corresponding to the letter "a".

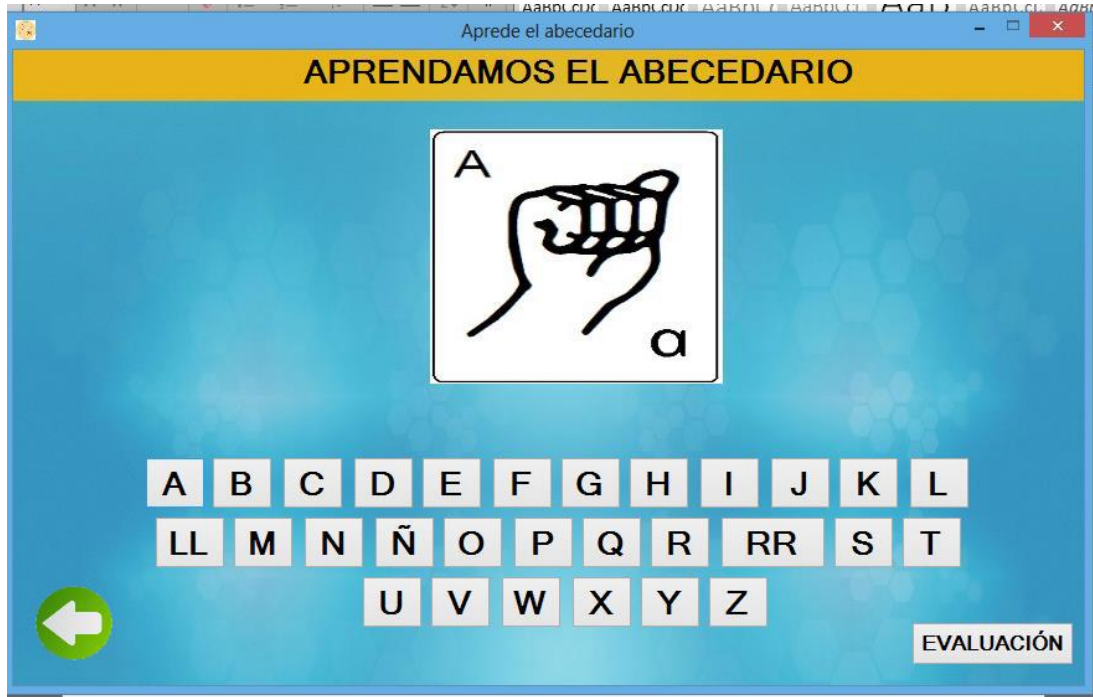

Fig. 3 Screen to learn the alphabet.

Similarly, in the lower right corner of the "learn the alphabet" window there is the "assessment" button, that starts a test, whose purpose is for the user to evaluate what has been learned in the sign language with respect to the alphabet.

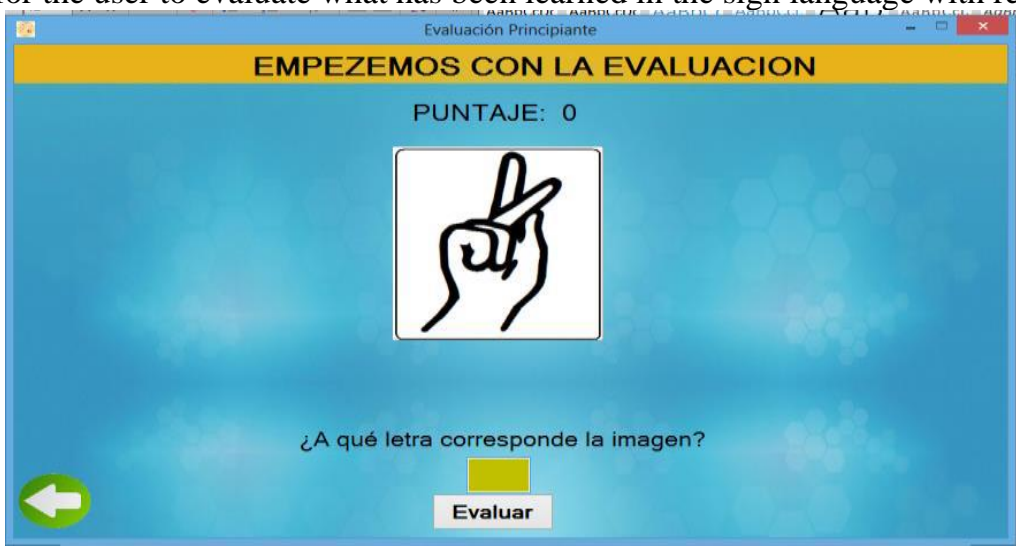

Fig. 4 Screen for assessing alphabet learning. 


\section{International Advanced Research Journal in Science, Engineering and Technology}

Vol. 7, Issue 11, November 2020

\section{DOI 10.17148/IARJSET.2020.71107}

If the user decides to take the test, a window is presented in which an image referring to the letter that the user is asked for will be shown. Next, the user will have to enter the letter to which the image corresponds in the text box and then press the "Enter" key, or click the evaluate button, to verify if the entered letter is correct, such as can be seen in Figure 4.

If the answer is wrong, it will return to the alphabet window so that the user can observe the letters again. If the answer is correct, the user is awarded five points, which will be accumulated until reaching a maximum score of 25 . Upon reaching said score, a congratulatory message will be displayed for finishing the test.

When the user takes the test and gets the maximum score, then he or she can continue with the learning of sign language at an intermediate level.

The Intermediate option has three learning sections called pronouns, family and greetings, which are learned in this order. Pronouns will be learned first, while the others remain locked. Once learned pronouns the access to the family section will be granted, and the last one to be unlocked is the greetings section.

When the window corresponding to the pronouns section is presented and by clicking on the corresponding button, the user is presented with a window similar to Figure 5 to learn the pronouns. In this window the signs to be learned will be displayed, to do this, click on the first pronoun, then the second and so on until the option for the next section is unlocked to continue with the learning of family, and so on until greetings, as shown in Figure 6.

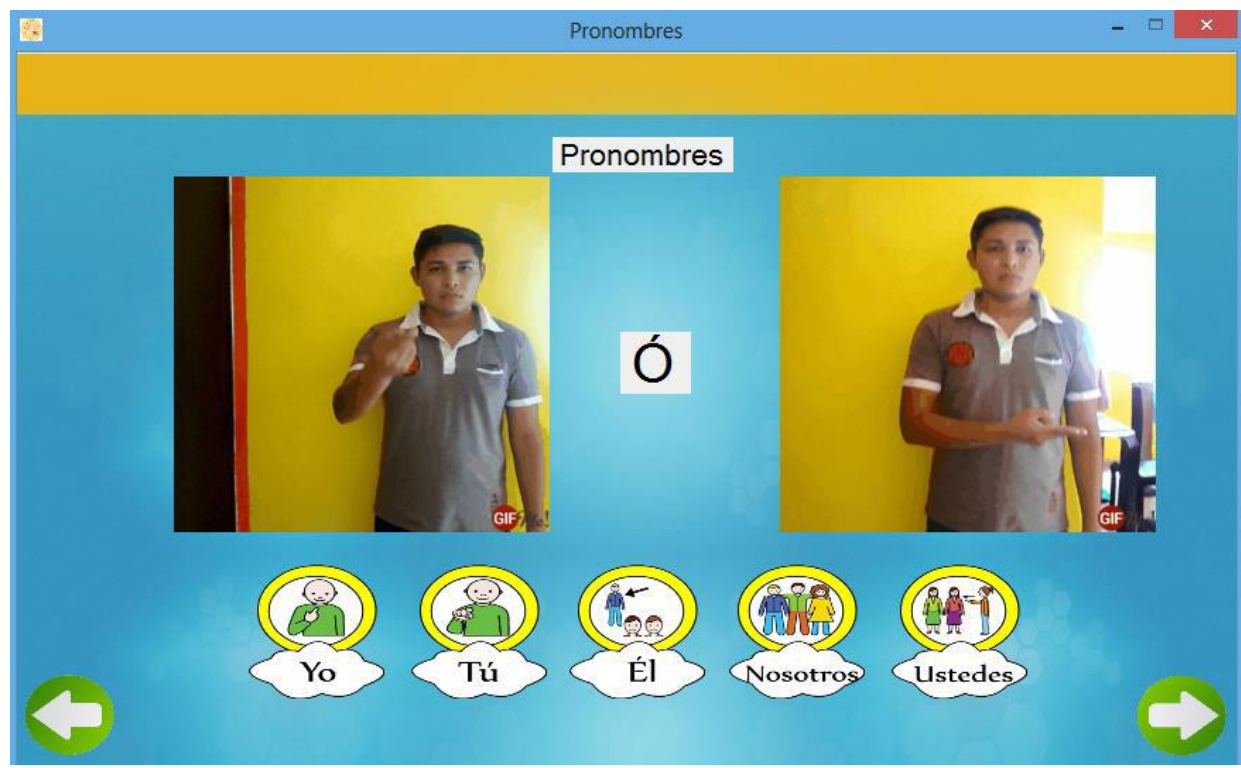

Fig. 5 Screen to learn the pronouns.

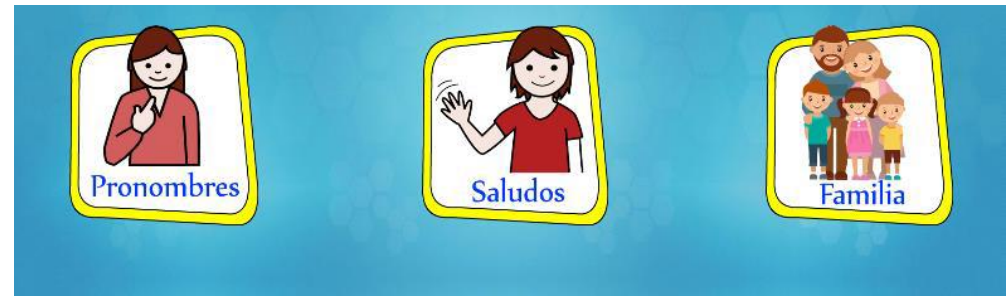

Fig. 6 Screen to learn the pronouns, family and greetings.

Finally, regarding the instructions option, it contains, as its name indicates, a set of instructions to use the software. In Figure 7 can be seen the image corresponding to the window of this option. 


\section{International Advanced Research Journal in Science, Engineering and Technology}

Vol. 7, Issue 11, November 2020

\section{DOI 10.17148/IARJSET.2020.71107}

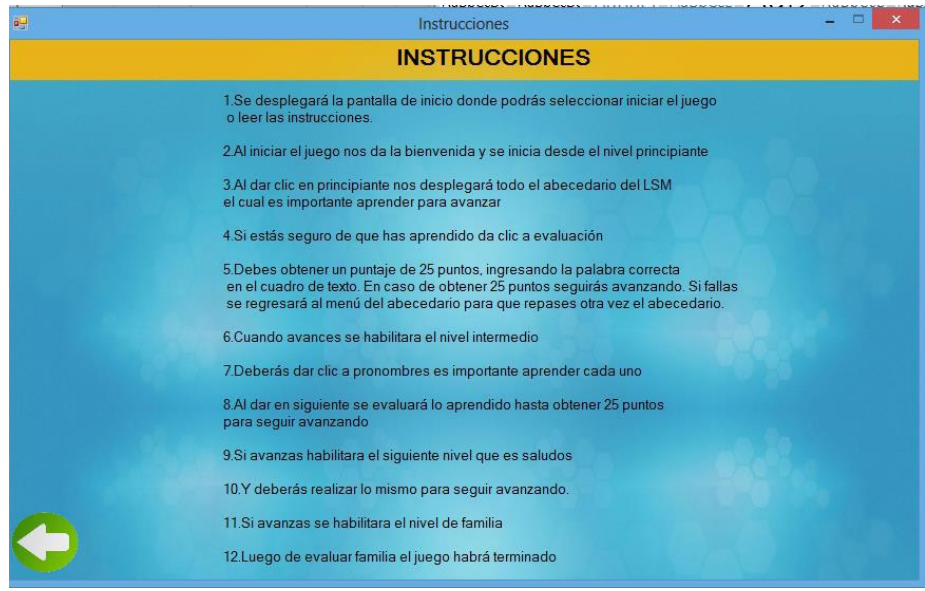

Fig. 7 Screen with instructions to use the software.

\section{EXPERIMENTS}

The software was evaluated with elementary-level children to whom the software was presented and given instructions on how they should use it. The children interacted with the system for a certain time to later take the test included in the software.

The sample used in this work was of five children, who are close neighbors to the home of one of the software developers. The foregoing, due to the health situation that we are currently experiencing worldwide. The children stated that it was not difficult for them to use the software because they had previously used programs with similar interfaces and that they felt happy learning sign language because that would allow them to communicate although in a basic way with people who have a hearing impairment.

\section{VI.CONCLUSIONS}

Deaf children have the right to receive education in their natural language, however, sometimes they do not know how to communicate because they do not know a sign language. On the other hand, teachers, classmates, family, etc., also sometimes do not know the same sign language. For this reason, this work presents the development of a software with a friendly and attractive interface to make it easier for the user the learning of a sign language. The software has already been tested by several users who provided favorable comments to the graphical interface, although it is important to mention that it has not yet been tested on a large scale and in classroom environments to be able to listen to the observations and annotations of the users.

\section{REFERENCES}

[1] Kennewell S., Tanner H., Jones S., \& Beauchamp G. Analysing the use of interactive technology to implement interactive teaching. Journal of Computer Assisted Learning, vol. 24, pp. 61-73, 2008.

[2] Consejo Nacional para el Desarrollo y la Inclusión de las Personas con Discapacidad. Lengua de señas mexicana. Publicado el 10 de agosto de 2016. Disponible en https://www.gob.mx/conadis/articulos/lengua-de-senas-mexicana-lsm?idiom=es

[3] COPRED. Consejo para Prevenir y Eliminar la Discriminación de la Ciudad de México. Lenguas de señas son fundamentales para el desarrollo de las personas sordas y el acceso a sus derechos. Publicado el 23 de septiembre de 2019. https://copred.cdmx.gob.mx/comunicacion/nota/lenguas-de-senas-son-fundamentales-para-el-desarrollo-de-las-personas-sordas-y-el-accesosus-derechos

[4] COPRED. Consejo para Prevenir y Eliminar la Discriminación de la Ciudad de México. Día nacional de las personas sordas. Publicado el 27 de noviembre de 2020. Disponible en https://copred.cdmx.gob.mx/comunicacion/nota/dia-nacional-de-las-personas-sordas 